\title{
From critical to carbon neutral, grassroots sustainable urban planning
}

\author{
F. R. V. Monteiro \\ Faculdade de Arquitectura da Universidade Técnica de Lisboa, \\ Centro de Investigação em Arquitectura, Urbanismo e Design, Portugal
}

\begin{abstract}
This paper presents a case study developed by a research unit, named Less Carbon, More Renewable Energies and based in Faculdade de Arquitectura da Universidade Técnica de Lisboa, which pursues the goal of understanding how the carbon neutral challenge is changing the present day's urban and architectural practices. We have determined, as research methodology, the analysis of self-acclaimed carbon neutral and/or carbon reduction projects in order to detect which strategies, techniques or technologies can best be applied in different sites and contexts. For this particular case study, we studied "Masdar City", a carbon neutral city in the desert of Abu Dhabi designed by Foster and Partners, with the purpose of determining strategic sustainable guidelines to rehabilitate Cova da Moura, one of Portugal's three "critical neighbourhoods". Most data regarding both cases is very distinct considering both scale and economic conditions; however, we have detected a profound similarity in the core of the development's strategies, both case studies plan to invest in renewable energies to obliterate a current stigma and to guarantee an economic future. What proves to be unique about Cova da Moura is that it is a case of grassroots sustainable planning (planning from the bottom/up versus from the top/down) emerging in a poor, low-educated, neighbourhood, a fact that becomes even more evident when compared to the carbon neutral state-of-the-art development in Abu Dhabi.
\end{abstract}

Keywords: carbon neutral, Masdar, grassroots planning, Cova da Moura, solar energy, sustainable. 


\section{Introduction}

When we started this research, we were driven by the purpose of understanding how some of Masdar's carbon reduction strategies could be applied to a different cultural and economic situation. What surprised us during the course of this research is that Cova da Moura's residents had already determined as one of the neighbourhood's rehabilitation strategies the incorporation of a solar panel industry and training, as stated in an official protocol signed between residents and local powers [1]. We detected Cova da Moura was already using one of Masdar's core strategies: the use of renewable sources of energy as a structural pillar of an alternative economic future and as the means to invert an undesirable image of the community.

\section{From the colonial past to a renewable energies future}

This section presents how Cova da Moura and Masdar City have very different origins, economic contexts and physical dimensions; however, it also argues that despite these differences, both case-studies rely on a similar planning strategy based on two ideas: the use of renewable energies to reconstruct the economy and the need to promote a new image.

\subsection{Cova da Moura, the need to heal a post-colonial wound}

Cova da Moura is a neighbourhood located in Portugal, within Lisbon's Metropolitan Area with a present day estimated population of 5,500 residents and a total area of 16.5 hectares. The neighbourhood's site is characterized by steep topography, has a favourable solar exposure and is adjacent to one of Lisbon's urban train line stations. In 2005, the neighbourhood was classified as one of three "critical neighbourhoods" (Bairros Críticos) by the Portuguese government.

Throughout the past decade, Cova da Moura has been the object of three thorough surveys: the first, in 2002, developed by Cunha [2], the second by state authorities and municipal powers with the support of the residents [3] and the third by Laboratório Nacional da Engenharia Civil [4]. These three surveys provide extensive details regarding both the neighbourhood's culturally rich but low educated population and its poor housing conditions. The sources used for this paper have been these three surveys, on-site analysis, and interviews with residents focusing particularly on leading figures within the community's associations $[5,6]$.

In the early 1970s, Cova da Moura's present day site was mostly agricultural land belonging to private landowners. The neighbourhood's occupation began, in the 1970s, with half a dozen families. A pivotal event responsible for the neighbourhood's unplanned growth was the Portuguese revolution, in 1974, as presented by Raposo [7]. One of the surveys [3] reports today that, since its early beginnings in the 70s, Cova da Moura's original population was mostly made up of Portuguese population who had returned from African colonies, particularly 
from Cabo Verde. As the neighbourhood expanded, the African community kept its presence. Today, around $40 \%$ of the present day population has migrated from former African colonies. [3]

Cova da Moura's origins, in the 1970s, explain the neighbourhood's present day critical condition. Occupation was done not only without licenses or building permits but without the legal owners' permission. The landownership issue remains today unresolved; however, it is relevant to contextualize historically this illegal occupation. In 1974, Portugal began the transition from a dictatorship to a democratic regime. With this transition came a process of decolonization forcing the Portuguese population residing in the colonies to leave their homes and fortunes behind. As we reported in interviews with local residents who had lived in Cova da Moura since the 1970s [5], in most situations, families came from the colonies with nothing but the need to support a family. This migrant population had to rebuild its future with little state support, as the country itself was undergoing a turbulent revolutionary process.

As stated in the survey developed by public authorities [3], today, there seems to be a consensus that State should not only support the expenses of expropriating the proprieties from the five present day private landowners but also acknowledge the rights of the residents. However, in 2002, a master plan presented by the city hall prior to the survey, contemplated the demolition of three fourths of the neighbourhood [2] and the relocation of the residents. Residents managed to come together to stop the master plan; however, as expressed by community leaders [5, 6], today, one of the neighbourhood's greatest concerns remains legalizing landownership. Without legal ownership, building permits to rehabilitate housing and infrastructure can not be attributed, leading to an even greater degradation of already frail physical conditions. LNEC's [4] survey of housing conditions concludes that, of the surveyed 2000 units, $10 \%$ of the buildings are not in habitable conditions; furthermore, proximity of the housing leads, in some situations, not only to a lack of privacy, but to irregularities in what regards safety regulations.

Cova da Moura's turbulent origins have led to strong ties between residents who found support in each other. Today, the neighbourhood is prolific in associations of residents, the first of which was created in the 1970s. Since then, these associations have been fighting for basic needs such as water supply, sewer system, electricity and a primary school. As residents proudly boast $[5,6]$, the entire neighbourhood has been built with their own hands. When there is a need to build something, such as stairs to help overcome a path's steep topography, residents call for a Djunta Mo (meaning holding hands) operation [6].

\subsection{Masdar, the need to create a post-oil society}

Masdar City was conceived to be carbon neutral, zero-waste, car-free city for 40,000 residents and 50,000 daily commuters. The city is located in the desert lands of Abu Dhabi, close to the international airport.

The construction of this project has begun in 2006 and some of its key equipments hope to be concluded in 2011. The city will occupy an area of six million square meters [8]. Even if the city is still under construction, it has 
already been the object of several studies; hence, literature reviewed to understand Masdar includes information supplied by the official website of the developer (Abu Dhabi Future Energy Company) [9], the official website of Foster + Partners, the architectural firm responsible for the master plan [8], several newspaper articles focusing on the ambitious scale of the development, and scientific articles [10,11] focusing on specific issues regarding energy policies and technological innovations.

The city is an initiative of the Abu Dhabi Future Energy Company (ADFEC). The name "Masdar" means "the source" as the city aims to become a showcase of state-of-the-art technology regarding alternative energy sources. As stated in the company's website: “One key objective of Masdar is to position Abu Dhabi as a world-class research and development hub for new energy technologies...A related objective is to drive the commercialization and adoption of these and other technologies in sustainable energy, carbon management and water conservation. In doing so, Masdar will play a decisive role in Abu Dhabi's transition from technology consumer to technology producer." [9]

As noted by Reiche [12], Masdar will not be the world's first carbon neutral project to be built, as at times information provided by the company or by newspaper articles claims [12, 13], what is unique about Masdar is its impressive scale $(90,000$ people and six million square meter) and its ambitious programme hoping to include key institutions in renewable energies and more than 1500 companies in the field of sustainable energy technologies. The city plans to become a global hub for scientific and corporate activities concerning energy technologies.

The city is still being built; hence, it is too early to analyse the effective feasibility of this highly technological future. However, ADFEC has already confirmed that Masdar City will include the following key equipments: (1) the new global headquarters of the International Renewable Energy Agency (IRENA); (2) the Masdar Institute of Science and Technology (MIST) developed in cooperation with the Massachusetts Institute of Technology (MIT) offering, since the start of the current academic year, Master's and Doctoral-level degree programs focusing on the science and engineering of advanced energy and sustainable technologies [9]. Regarding the desired presence of 1500 companies attracted by the tax-free policies, Masdar city has already started attributing licenses for companies to operate from Masdar City, namely it has attributed a license to the Neutral Group a carbon abatement consulting and execution, a company with offices in London and New York [9].

\section{Sustainable planning from the top-down versus sustainable planning from the bottom-up}

\subsection{Masdar, sustainable planning from the top-down}

The United Arab Emirates is a federation of seven emirates, created in 1971, of which two (Abu Dhabi and Dubai) have more power than the other five. Abu Dhabi's ruler is the president, head of state, of the UAE and the ruler of Dubai is 
the prime-minister (head of government). The Supreme Council of the UAE includes all seven emirs but only the rulers from Dubai and Abu Dhabi have veto power on affairs of national interest. As noted by Reiche [12], UAE is not a democratic country since most legislative and judicial positions are still appointed by the emirate rulers; hence, Reiche concludes, most power is still with the emirate rulers and their families. Within the UAE, Abu Dhabi is not only the largest and most populated emirate but also the owner of $95 \%$ of the country's oil resources [12].

The decision to build this project was taken by the UAE leadership. The Abu Dhabi Future Energy Company, established in 2006, is today wholly owned by the government of Abu Dhabi through the Mubadala Development Company. [12] The economy depends on fossil fuels and rulers want to secure a pos-oil future where Abu Dhabi maintains a position as global energy leader.

The country is also one of the world leaders in carbon emissions (measured in tonnes per person) according to Abu Dhabi's National Oil Company [15]. The Masdar Initiative, promoted by a powerful and highly educated community, aims not only to secure an alternative economy for the UAE, but also to promote a new image of the nation as a leader in renewable energies and carbon reduction strategies.

\subsection{Cova da Moura, sustainable planning from the bottom-up}

The unresolved issue of landownership and the neighbourhood's institutional isolation has accentuated Cova da Moura's strong sense of identity; however, the frail physical conditions associated to the social enclosure have accentuated the neighbourhood's negative image. One of the surveys [3] regarding the image of the neighbourhood revealed that those who live in Cova da Moura have a positive image of the neighbourhood while those living outside have a negative image. The residents' associations have strived to change the image of the neighbourhood by promoting cultural events and even guided tours presenting the neighbourhood's rich musical traditions, restaurants specialized in dishes from different African countries, and an unusual quantity of specialized hairdressers; however, one of the neighbourhood's most ambitious initiatives is the construction of an industry of solar panels within the neighbourhood, providing jobs and training for residents.

This initiative started, in 2003, when one the community's members attended a conference promoted by Equal (an initiative promoted by the European Social Fund [17]). The speaker of the conference was Sanjit Bunker Roy, the founder and director of the Social Work and Research Centre in India, also known as the Barefoot College. As indicated in the College's website [16] Barefoot College provides training to both rural unemployed youth as well as semi-literate and literate rural women. The purpose of Barefoot College is to turn a low educated workforce into Barefoot college's solar engineers who become apt not only to install and maintain solar home lighting systems but also to produce solar lanterns. The information regarding this project was collected in interviews [6] and in documents with the project budget provided by Moinho da Juventude. 
In this conference in 2003, Cova da Moura's residents met Sanjit Bunker Roy and organized a visit to the College in India in order to observe, understand the College's methodologies and formalize a protocol. The goal was to bring one of the Barefoot College teachers to Lisbon to provide training and to transform the neighbourhood's low educated population into solar engineers. Residents were relying on a fund (Progride) which was put on hold when the neighbourhood was officially declared to be a "critical neighborhood", in 2005.

In 2006, the actions required to rehabilitate Cova da Moura were stated in a protocol signed by 25 associations and institutions [1]. These 25 associations included the residents' associations; local, municipal and State powers; and several public institutes from distinct social fields (police force, immigration, art and culture, unemployment, drug addiction, health, welfare and education). This protocol determined eight rehabilitation strategies, one of which is environmental awareness. The environmental awareness strategy determined as required actions: "a) to provide residents with competences in the construction and maintenance of solar panels and other equipments based on alternative energies; b) to create small industries able to produce equipments based on alternative energies; c) to include solar panels and other equipments based on alternative energies in the neighbourhood's rehabilitation; d) to establish protocols with design practices related to sustainable architecture." As predicted in the protocol, actions should be concluded by 2011 .

\section{Conclusions, a future of grassroots sustainable planning}

Even if most of its ambitious goals are still on paper, Masdar City is an initiative with an impressive scale which our research group aims to keep monitoring throughout construction. However, what we have discovered on the lower end of the economic spectrum is the possibility of bottom-up sustainable planning. Both Abu Dhabi's leaders and Cova da Moura's community use a similar strategy to guarantee an uncertain future. Both aim to be part of the renewable energies industry in order to provide economic sustainability and to alter the perception outsiders have of the community. What is particularly interesting in the bottomup initiative taken by Cova da Moura's residents is that it can be used as evidence that our common future does not need to originate from within an educated and financially powerful political system. A renewable energy planning strategy can arise from within any committed community.

\section{References}

[1] (no author), Protocolo de parceria, âmbito da Iniciativa "Operações de Qualificação e Reinserção Urbana de Bairros Críticos”, prevista na Resolução do Conselho de Ministros $n .^{\circ} 143 / 2005$, de 7 de Setembro entre todas as entidades envolvidas na execução do Programa de Intervenção 2007-2011 para a Cova da Moura, no concelho da Amadora, pp.12-16, 2006. 
[2] Cunha, V, Estudo de Caracterização / Diagnóstico do Bairro do Alto da Cova da Moura. Lisboa: 2002

[3] Malheiros, J. \& Vasconcelos, L. \& Alves, F.S. (eds.) Operação da Cova da Moura - Volume 1, Diagnóstico Iniciativa Bairros Críticos. Lisboa: 2006.

[4] Vilhena A. \& Coelho, A.B., Colaboração do LNEC na Análise das Condições de Habitabilidade do Edificado no Bairro do Alto da Cova da Moura. Avaliação das necessidades de reabilitação do edificado Relatório Síntese, Laboratório Nacional de Engenharia Civil: Lisboa, 2008.

[5] Lieve Meersschaert, Personal Communication, 25 September 2009, member and leading figure in Associação Cultural Moinho da Juventude

[6] Ilídio Carmo, Personal Communication, 25 September 2009, President of Associação de Moradores do alto da Cova da Moura,.

[7] Raposo, I. Intervenção Pública num Bairro "Crítico", o Alto da Cova da Moura. Proc. of the 4th International Seminar on Architecture. FAUTL: Lisboa, 2009.

[8] Foster+Partners, www.fosterandpartners.com.

[9] Masdar, Abu Dhabi Future Energy Company, www.masdar.ae

[10] Walsh, B, Special Report: Energy, Desert Dreams, Time, Feb 252008

[11] Revkin, A. Car-Free Solar city in Gulf could set a new standard for green design, The New York Times, Feb 52008

[12] Reiche, D., Renewable Energy Policies in the Gulf Countries: a case-study of the Carbon Neutral "Masdar City" in Abu Dhabi, Energy Policy, 2009, doi: 101016 / j.enpol.2009.09.28

[13] Nader, S., Paths to a low-carbon economy - the Masdar Example, Energy Procedia 1 (2009) doi:10.1016/j.egypro.2009.02.99

[14] International Renewable Energy Agency, www.irena uae.com

[15] Abu Dhabi National Oil Company, www.adnoc.ae

[16] Barefoot College, www.barefootcollege .org

[17] Equal, www.equal.pt 